\title{
J
}

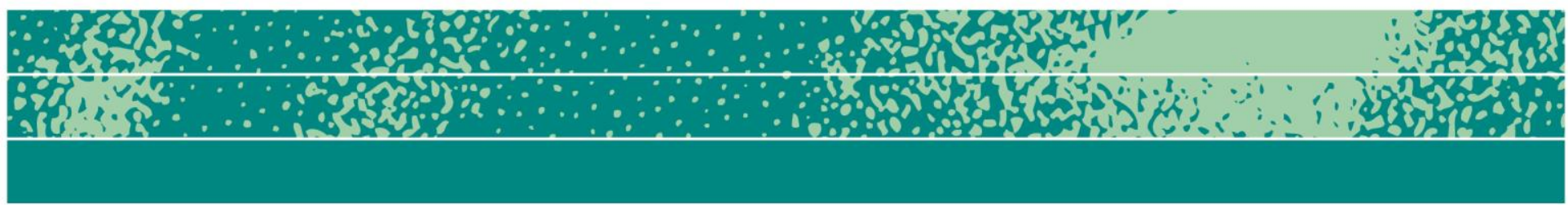

Essay

\section{Everyday things: an anthropologist's take on emotion and the sense of the sacred in consumer rituals}

\author{
Tom Maschio
}

I was originally trained in the anthropology of religion and did my first fieldwork in Papua New Guinea, studying a Melanesian people's ritual and religious life and trying to understand their sense of the sacred. The work I've carried out the last eighteen years as a business consultant studying consumer culture has turned out to be not so very different from my previous work. This may give people in both anthropology and advertising pause, but to me, and to other commentators, consumer culture is often a search for meaning, not merely a search for material comfort or fun or pleasure or status or an attempt to satisfy basic necessity. The next thought may also give pause: that the search for meaning is often a search for the sense of the sacred in the everyday-the everyday product, the everyday activity. In categories as varied as pet food, bicycles, credit card use, food, and electronics, the successful product or brand often gives people a sense of what can only be described as the sacred in the everyday. This sense is a strong emotional benefit for consumers, the creation and evocation of which is an important objective of the rituals and routines that surround product usage. This emotional
Page 1 of 10

JBA 4(2): 342-351

Fall 2015

(C) The Author(s) 2015

ISSN 2245-4217

www.cbs.dk/jba 
benefit provides certain brands and products with what Malcolm Gladwell would term "stickiness," or memorability. Likewise, anthropologists who write about the workings and objectives of religious ritual tell us that ritual is one way cultures highlight and make memorable for participants certain values, meanings and feelings.

The anthropologist Gilbert Lewis writes that "the idea of the deeper significance of ordinary things is familiar to those who take part in the study of ritual" (Lewis 1988:30). Ritual places ordinary things within a special field of meaning so that participants will pay attention to them. As Lewis puts it, during a ritual:

"Instead of seeing an object or action in a conventional way we un-gate our vision and search out its special qualities, which have no relevance in the ordinary economy of our perceptual and practical dealings with it, but which by close attention, by some sort of short circuit of thought, may provide an intimation of a mystery" (Lewis 1988:31).

In this way ritual creates the sense that the object attended to is something memorable, complex and symbolic of deeper values, and something of the sacred attaches to it.

I've often used anthropological theories about religious ritual to help me understand consumer thoughts and feelings about their preferred products and brands. I've tended to view the rituals and routines that consumers create around products and brands as affirmations that these objects are special and deserving of sometimes quite intense attention.

When I first wrote a version of this essay these thoughts intersected with what was one of the most central questions of the past economic recession for businesses: what can we learn from products and brands that were performing respectably, if not profitably, in the midst of a severe economic downturn? Why do consumers remain attached to some products and brands and categories and not others in rough economic times? In many cases it has to do with this feeling of meaning in the everyday and with the concept of ritual. Put another way, certain brands stand out from others in the same category because they have been particularly successful in allowing consumers to tap into the sense of the sacred in the everyday. And, I believe, more products would be successful if advertisers understood the meanings of the rituals that attach to specific product categories.

My overriding objective in writing this piece is, hopefully, to suggest a promising approach to the study of consumer culture. I wish to argue that one of the ways that advertising can better understand the emotional benefits of specific product categories and then more crisply articulate these benefits in communications strategies about specific brands is to leverage a particular anthropological approach to ritual. 
Anthropological definitions of ritual are varied and complex, as are the definitions and approaches that anthropologists have used when considering consumer rituals, and I will consider a few of these here.

\section{Revelations about the everyday: performance and emotion in consumer rituals}

The subject of the ritual aspect of everyday occasions was most famously discussed by Goffman (1955) through his analysis of "facework." Facework is the seemingly choreographed, standardized interactions between people striving to create, maintain or preserve "face" or self and social image. Facework is a ritual of social interaction. Mauss would have called this maintaining the persona-the person's reputation, social role, social position; the view he carries of himself into the social arena and displays to the world.

In consumer research Rook (1985) considered the symbolic and ritual elements of personal grooming, after having criticized consumer and marketing studies for failing to consider adequately the symbolic dimensions and meanings of consumer actions (1985:251). For both authors the element of sacredness in everyday occasions and activities is implicit. For instance, for Goffman the person is the seemingly sacred object of the interaction ritual, whose face, honor, reputation and selfimage must be maintained through performance. The telos or goal of the ritual is face maintenance, almost at all costs. In an interesting parallel from consumer studies, Rook points out how people often work toward realizing a more ideal self-image through their grooming patterns and use of consumer items and brands. There is something charged in the selfimage people are trying to attain or continually recreate in their stereotypical and patterned grooming activities, as I have seen in projects I've carried out on hair care brands and products, and as Malefyt's analysis of men's shaving rituals reveals (2015:704-21). When reading these scholarly accounts, and my own business reports, I remember how a sense of enthrallment often animated and colored peoples grooming activities, the techniques they used to carry out these activities and the objects, substances and brands that they used.

In another example, Sherry (1983), drawing on Mauss's seminal work The Gift, outlines the stereotypical stages and interactions of holiday gift giving. He does not directly broach the idea of sacredness in his piece. It appears however that people engage in these interactions to achieve an ideal of sociality, even social harmony, almost as if they are working toward realizing a sacred ideal. In a related vein Wallendorf and Arnould (1991) draw on Durkheim's ideas as they outline the social functions and meanings of the ritualistic Thanksgiving Day meal. The feast draws family together and celebrates family history and lore. This is a rite of intensification centered on consumption and food, often represented by "down home" or everyday commercial brands and foods. These brands 
resonate with the informal "communitas" of the feast while also celebrating the culturally important correlation of abundance with family. Family is abundance on a number of actual and symbolic levels during Thanksgiving-abundance of sentiment and feeling, abundance of concern symbolized by food abundance, by the abundance of the feast.

Yet, I believe that some of these treatments do not make explicit enough the idea of enchantment in relationship to consumer and other everyday rituals. Enchantment entails a type of thralldom; it entails seeing the everyday thing or activity in a heightened fashion, thus seeing or perceiving some deeper meaning and even mystery in them. Malefyt's argument about the sensory elements of shaving for one class of shavers-we would perhaps call them ritual adepts-certainly brings this idea of enchantment to the fore. But Malefyt's main brief is to outline a way of marketing the senses, introducing the anthropology of the senses to corporate anthropology (Malefyt 2015: 710-716). He references anthropological work that shows how "culture specific concepts and practices of a people's sensory experience generate day-to-day social interaction and mark what is meaningful in life" (2015:707). But the idea of "sacredness" remains implicit, and the word sacred unspoken. To build on Malefyt's argument, the sensory qualities of ritual alert participants to the fact that they have left the realm of the prosaic; that some special meaning attaches to the activities they are witnessing or carrying out; that they are entering a special arena.

Being a New Guineaist I am well acquainted with ritual activities that are meant to reveal the true or deeper meaning of everyday things and activities to, for instance, initiates. In one initiation rite I observed and studied in New Guinea, common place objects were presented to initiates, sung about, had the names of their different sections revealed and generally were shown to have cosmological and sacred significance, as were the everyday activities in which they were used. This significance had to be absorbed in manifold ways if the initiates were to progress as persons, and move to a different and enhanced social status (Maschio 1994:104-139). To make the connection, I do believe consumer rituals often reveal people to be engaged in performances that enable them to see or perceive or create the deeper meanings of their everyday activities and of the objects they interact with. Further, these rituals have an emotional payoff and objective. They are often emotionally satisfying to perform, and their performance is meant to evoke certain emotional states. During these performative sequences people reflectively add depth and meaning to their everyday lives and thereby, as perhaps Geertz would say, establish pervasive moods, motivations, feelings and emotions in themselves (1973:119-120)

So, I am thinking about the performative, the theatrical, and the aesthetic and emotional elements of ritual. In general I am framing consumer rituals as performances carried out according to the directions 
of almost theatrical scripts that are meant to move an audience emotionally (whether an audience of one-oneself-or of many) through symbolic language, with the aim of heightening the meanings of objects, activities or aspects of life. After all, the early anthropological definitions of ritual discussed its concern with the realm of the sacred, and with the consecration of objects, as in the work of Durkheim. I do not feel that we should shy away from these insights simply because we are dealing with consumer culture, a realm not as profane as critics often portray it to be. If we are going to use the concept of ritual, let's use the concept of the sacred as well. Let me illustrate how these ideas apply to the study of consumer culture by discussing the rituals that consumers weave around some common product categories: pet care and bicycles. Nothing is seemingly more every day than feeding your cat or riding your bike.

\section{Cat food and cat mana: a bit of category history}

U.S. cat food sales increased 12.3 percent in the six months ending November 2008, with sales increases holding steady toward the end of that recession year, just when the US economy was cratering. Sales of catcare related paraphernalia (kitty condos and the like) had also increased dramatically over the course of the recession. What to make of this when many people were worried about having enough money to keep their homes and buy food for their human families? A series of ethnographic projects I carried out on pet care, and peoples' attitudes toward their pets and pet food brands, was revealing.

We all understand that the intimate physical interactions between cats and their owners-during petting, playing and grooming-produce feelings of connectedness, peace and security for owners and their cats. Many people feel that cats put them in touch with their own animal nature, enabling them to experience simple animal contentment, such as when their cats sit on their laps purring. But beyond this, cats fascinate their owners because they seemed to possess some uncanny, exotic, magical quality. Though my respondents were not familiar with the idea, I would say that they perceived that their cats possessed mana. In the anthropological record of diverse cultures, mana is a religious concept that represents the principles of efficacy and power. And people often describe their cats as extraordinary, efficacious animals, possessed of capabilities that provide a window into the natural world. For instance, cats appear preternaturally athletic to cat lovers. They also seem to possess amazing and mysterious sensory abilities and even aesthetic qualities. Their beauty somehow indicates their discerning nature. One of the pet owner's most important concerns is nurturing cat mana through the choice of the right pet food. Some want their cats to really act like cats-which means exhibiting mana. This is one of the ways that owners experienced a sense of wonderment, or sacredness, in the everyday. Driving cat food sales is a powerful consumer need to cultivate cat mana 
and to see it exhibited in cat play and other behaviors.

Owners often feel a real species distance between cats and themselves. Unlike dogs, whose internal states are thought to be much more easily read, cat behavior provides only teasing indications and ambiguous signs of a mysterious nature that owners struggle to interpret. It is this desire to make contact and to divine cat nature that drives human/cat interaction, and in some very interesting ways. Owners value the presence of this enigmatic creature within their homes, especially noting cats' behavioral interactions with domestic spaces.

\section{A sense of the sacred in the home}

Many cat loving owners also speak of the symbolic link between the nature of cats and the nature of home. Cats introduce a world of physicality, play, amusement, spectacle and sentiment into the home. Paradoxically, having a pet cat is one of a number of ways that people seek to humanize the home. Cats make a house feel lived in. They do this by investing something of themselves in it when they take possession of our domestic spaces. A favorite sleeping place in a bookcase, a particular nook or cranny of the house, a preferred room or bed or chair, and the cat's daily visiting of these special places enhance the owner's sense of hominess. Often the cat owner will embellish these spots with toys, scratching posts, personalized pillows or little beds. As an anthropologist of religion, I view these commercial embellishments as shrines to essential cat nature. In this way owners are symbolically expressing the idea that their cats are sanctifying their homes, weaving a sacred hominess into everyday experience, enabling them to experience domesticity more vibrantly and richly.

The shrines that cat owners build to their cats become the stage on which cats then perform, and cat owners interpret cat behavior as if it were a ritual performance. A cat's daily rounds through the house, its feeding and play behavior, have a repetitive and ritualistic quality that owners find highly satisfying. It is as if by engaging in its daily routines the cat renews the sense of domesticity and sacredness in the everyday. Owners feel they are participating in this ritual by furthering its performance. As one respondent put it:

"I want to provide a sense of security and contentment to our cat. Cats like to be in control of their environments. I feel amusement in their cat places and I feel pride that they I have cared for them enough so that they have taken ownership."

When cats came to possess the domestic realm in these ways, owners feel themselves to be closer to their cats and to have made a real connection with them. 


\section{High-end bicycle brands}

I have done this sort of exercise in ferreting out the sacred meaning of the everyday product or service in many projects that I have worked on. As I have done so I have continually made use of the concept of ritual.

It is a truism at this point to note that consumers create rituals and routines around products and brands. From an anthropologist's perspective, the brand ritual is a type of cultural performance (as a play is a performance) through which consumers express meanings and sentiments, not only about the brand itself but about larger cultural issues. In the study of cats and cat food brands, as consumers talked about cat food brands and other cat care products, they expressed ideas about domesticity, the nature of a sacred animal, and their understanding of mana (all well-established topics in anthropology). This brings us to another point about consumer and other sorts of ritual performance: that they can reveal whole worlds of meaning, mapping back to many culture domains.

Let me turn to another example in another category: high-end bicycle brands. In one commercial project I found that riders were expressing ideas about competitiveness, energy, play, discipline, freedom and beauty, as they purchased, raced, trained on, customized and repaired their bicycles. These ideas often weren't expressed directly but were encoded in symbols. Thus, design elements of a bicycle came to symbolize energy, lightness, and strength. On a deeper level, the frame of the preferred bicycle brand served as a metaphor for how riders wish to think of their own, actual physical bodies-strong, light but fit, and trained to a fine edge.

Like a dramatic play a brand ritual usually has an overall theme or message. In the bicycle ethnography I arrived at the theme of "alignment"-riders attempting to align bicycle design into a close fit with their own physical bodies. Riders are continually customizing their bicycles to fit their own particular body types, to suit the type of race they were preparing for, and to be concordant with the sort of training routine they were practicing. As they do this they are also remaking their bodies, making their bodies more concordant with the shapes and contours of their bicycles. I took this process of embodiment to be the cyclist's brand ritual (as he usually felt he could carry it off with his preferred bicycle brand) and went about decoding it as I would any other ritual performance.

One other aspect of ritual is its formality, especially when compared to routines, as Lewis points out (1988:19-22, 25). In actual religious ritual there is often a certain rigidity or formality of gesture, as well as formal decorations, singing, the use of special costumes, masks, and special smells like incense, all of which alert participants that they have entered a special performance arena. These involve some of the dimensions that Malefyt discusses in his work on the sensory elements of 
brand rituals. Certainly the elaborate costumes of the cyclist and all his specialized, repetitive training rituals have a formality and ceremonialism to them.

The ultimate purpose of the cyclist's brand ritual is to hallow the activity that he is engaging in (bicycle riding and racing) through the means of his bicycle brand. This is how he creates and elaborates a sense of the sacred in his everyday and seemingly completely secular, banal training activity. I do mean everyday, as the training regimes of competitive riders are nothing if not regular and disciplined. The brand ritual, like a religious ritual, has an ultimate emotional objective for the participant that he, or she, wishes to experience again and again. For the cyclist this is a sense of transcendence and freedom that riding and racing delivers, once one is trained up and ready to compete. For the cat owner it is the sense of wonder at sharing one's home with a sacred, mana-filled animal, and the enhanced sense of domesticity that their cats allow them to experience.

\section{Discussion}

My take on why consumer products and brands can become "sticky," memorable, in a recession and at other times, then involves unraveling an apparent paradox. This is that a sense of the sacred, more than simply a sense of meaning, can be derived from the most ordinary things-that product category or brand rituals are often about the hallowing of some life arena and activity. Can it be that consumer culture is sometimes a façade for what can only be called religious impulses, or a screen upon which those impulses are projected? Thinking of the swath of profane consumer categories that I have subjected to anthropological analysis-cat foods and bicycles, cars, credit cards, toothpaste, underarm deodorant, skin moisturizers, feminine hygiene products, car parts (one could go on and on)-such a thought gives pause or brings to mind the old topic of commodity fetishism. Of course an atheist might call a particular religious object a fetish; certainly he would feel that believers feel inappropriately or mistakenly enthusiastic about, say, images of the Virgin Mary. The bookend and response to the idea of fetishism, however, is the religious intuition about the deeper significance of everyday things. And indeed "the deeper significance of ordinary things is familiar to those who take part in the study of ritual" (Lewis 1988:30). Certainly it is familiar to me. As I have said, many of the religious objects I studied in New Guinea seemed at first glance no more promising candidates for ritual treatment. In one ritual I've written on, a female initiation rite, the ritual objects were areca nut, lime, small clam shells, common plants of various sorts, pig tusk ornaments, dogs' teeth, cassowary quill necklaces, and grass skirts (Maschio 1994:105-139; 1995:131-161).

It's what people do with these common things, both here and elsewhere, that give them their particular meanings, regardless of what 
the things are in and of themselves. More often then not people are weaving them into ritual performances.

Of course I've never used the word "sacred," or the phrase "religious ritual" in any of my business reports and presentations. But these phrases and ideas have often informed my thinking. This has been my secret.

The account planner for the the bicycle project leveraged the idea of the competitive cyclist's ritual, which included the notion that cyclists are in a constant state of physical refinement and personal transformation, to see biking as a way to access new experiences. Like me, the planner eschewed over-the-top references to "sacred experience." Rather, the planner and his agency stressed the thoughtful, purposeful elements of the cyclist's behavior and attitude-the fact that the cyclist perceived his ritual of alignment to be the cultivation of an intellectual skill. They then sought to portray brand attributes in intellectual terms, portraying the brand as a thoughtful brand that innovates on its own time frame, just as riders develop a thoughtful training program through their ritual of alignment. Their presentation secured the account. The innovation company I worked with on cat foods and cat care assimilated the idea of mana to the idea of super foods, stressing the nutritional power and efficacy of new cat food product offerings. The idea of manafilled cat nature was given a nod in communication strategies with the phrase "super cats"-super foods for super cats. This was all tied in to the sacred domestic symbolism of cats via a notion of parallel play-the idea that owners perceive cat nature to reveal itself as they watch cat play and cat routines go forward in domestic settings. The brand thus was portrayed as nurturing true cat nature. Years later some of these same ideas were used again in an advertising campaign for a specific cat food brand in the client's portfolio.

\section{References}

Durkheim, Emile. 1961. The Elementary Forms of the Religious Life. New York: Collier Books.

Geertz, Clifford. 1973 The Interpretation of Cultures. New York: Basic Books.

Gladwell, Malcolm, 2000. The Tipping Point: How Little Things Can Make a Big Difference. New York: Back Bay Books/ Little Brown and Company.

Goffman, Erving, 1967. Interaction Ritual: Essays on Face-To-Face Behavior. New York: Pantheon Books.

Lewis, Gilbert, 1988. Day of Shining Red: An Essay about Understanding Ritual. Cambridge: Cambridge University Press. 
Malefyt, Timothy, 2015. "An Anthropology of the Senses: Tracing the Future of Sensory Marketing in Brand Rituals." In Handbook of Anthropology in Business. Rita Denny and Patricia Sunderland Eds., pp 704-721. Walnut Creek, CA: Left Coast Press.

Maschio, Thomas, 1994. To Remember the Faces of the Dead: The Plenitude of Memory in South Western New Britain. New Directions in Anthropological Writing. Madison WI: University of Wisconsin Press.

Maschio, Thomas, 1995. "Mythic Images and Objects of Myth in Rauto Female Puberty Ritual." In Gender Rituals: Female Initiation in Melanesia. Nancy Lutkehaus and Paul Roscoe Eds., pp 131-161. New Jersey: Routledge.

Rook, Dennis, 1985. “The Ritual Dimension of Consumer Behavior." In The Journal of Consumer Research 12: 251-264.

Sherry, John 1983. "Gift Giving in Anthropological Perspective.” In The Journal of Consumer Research 10: 157-169.

Wallendorf, Melanie and Arnould, Eric J. 1991. "We Gather Together: Consumption Rituals of Thanksgiving Day." Journal of Consumer Research 18: $13-31$.

Tom Maschio has been a business anthropologist for the past sixteen years and head of his own consultancy (Maschio Consulting) since 2004. His consulting work has run the gamut of product and service categories and has been carried out mostly for Fortune 500 companies. His original training in symbolic and humanistic anthropology continues to undergird his approach to business anthropology. He originally carried out ethnographic research in Papua New Guinea and his experience there serves as an ongoing source of inspiration for his life and work. He can be reached at tom@maschioconsulting.com 